\title{
Correa Sutil, Sofía. 2005. Con las RIENDAS DEL PODER. LA DERECHA CHILENA en el siglo XX. Santiago: Editorial SUd AM ERICANA, 313 PP.
}

\begin{abstract}
El libro de Sofía Correa es un aporte importante a la literatura sobre la historia política chilena. Primero, porque a través del análisis de las características y el comportamiento de la derecha, explica aspectos relevantes de nuestro desarrollo político desde 1920. Segundo, porque abarca etapas de nuestra historia política que hasta ahora no han sido consideradas con la profundidad necesaria por la investigación académica, como es el periodo que abarca las presidencias de Carlos Ibáñez (1952-1958) y J orge Alessandri (1958-1964). Tercero, porque se centra en un actor político muy relevante y sobre el cual tampoco existe una amplia bibliografía.
\end{abstract}

A juicio de la autora la derecha siempre tuvo claros sus objetivos de largo plazo y siempre estuvo dispuesta a transar y ceder todo lo necesario para preservarlos. De esta manera, concluye que existen importantes continuidades entre la derecha anterior a 1973 y la actual, lo que estaría demostrado por la persistencia de un mismo proyecto y las semejanzas de los partidos que la representan.

El libro se divide en siete capítulos. En el primero se define a la derecha como la élite tradicional que dominó política y económicamente hasta la década de 1920, siendo los grupos económicos más influyentes - una élite cohesionada-, las grandes organizaciones empresariales, los partidos Conservador y Liberal y el diario El Mercurio sus principales expresiones.

Los tres capítulos siguientes analizan cómo los cambios acaecidos desde 1920 afectaron a la derecha y la actuación de ésta ante el gobierno del Frente Popular. El argumento es que la derecha desplegó una exitosa estrategia basada en la negociación y cooptación, papel que le permitió salvaguardar sus intereses de las reformas impulsadas por los gobiernos radicales.

Luego se estudian los desafíos que enfrenta la derecha en la década de 1940, explicándose que frente a la disyuntiva de definirse o por el "populismo social-cristiano", representado por el conservador Cruz-Coke, o por el capitalismo liberal, la opción de la mayoría de la derecha fue rechazar el proyecto populista. Ello, aun a costa de perder las elecciones de 1946 y favorecer la división del conservadurismo.

El rechazo inicial de la derecha al gobierno de lbáñez debido a su carácter populista también es materia de discusión en este libro. Así, se describe cómo, sin embargo, al terminar la etapa populista, hacia 1955, se produce un breve acercamiento entre el gobierno y la derecha, apoyando la aprobación legislativa del paquete de estabilización propuesto por Klein-Saks. Con todo, se explica que la derecha mantuvo distancia con el plan de esta empresa, pues no contenía un proyecto integral de reforma de mercado, lo cual sería su principal aspiración de largo plazo. 
Los capítulos cuatro y cinco son particularmente interesantes pues analizan la formulación que hace la derecha de su proyecto reformador y el intento de implementación en el gobierno de Alessandri. Respecto a lo primero, la derecha habría llegado hacia mediados de 1950 a compartir un proyecto de modernización capitalista, el cual debía sustituir al modelo desarrollado desde la década de 1930 que, sin embargo, ella misma había ayudado a establecer. A la formación de este consenso habría contribuido la pérdida de influencia política de la derecha (lo que la mueve a asumir una postura contraria al intervencionismo estatal), la influencia de economistas liberales estadounidenses y el papel jugado por El Mercurio, que desde la década de 1940 comienza a abogar por una reforma capitalista.

Para implementar ese proyecto, Alessandri forma un gabinete donde predominan empresarios, excluyendo a los partidos de derecha, los que, no obstante, lo siguieron apoyando. Su política apuntó a frenar la inflación, reactivar la economía, a la vez que se adoptan medidas de liberalización y reforma administrativa. A pesar de los buenos resultados iniciales, el programa, debido a diversas causas (el impacto del terremoto de 1960, incapacidad de atraer inversión extranjera, crisis de 1961), finalmente fracasó. Luego, se abandonó la idea de un gobierno independiente, a la vez que se debieron revertir varias medidas liberalizadoras e implementar otras, como una reforma agraria, que no eran parte del plan original.

En el capítulo siete se analiza la evolución de la derecha desde 1964. En primer lugar, se da cuenta de "la destrucción de la derecha histórica" a causa de su enorme pérdida de poder. Esta situación llevó a que en adelante la derecha desarrollara una estrategia confrontacional, de alta movilización y de acercamiento a los militares, prácticas que eran ajenas a su tradición. Igualmente, su discurso se vuelve muy defensivo, centrado ahora en el anticomunismo y no en la idea de una transformación capitalista.

En segundo lugar, se aborda la relación de la derecha con el régimen autoritario. Se destaca el apoyo total que esta le entregó, aun cuando sus antiguos dirigentes de partido no participaron de la elaboración y ejecución del programa neoliberal. Esto se explicaría por el hecho de que un proyecto liberal había sido articulado antes por ella, y por tanto la representaba. Segundo, se estudia la participación de una "nueva derecha" (surgida durante el autoritarismo), liderada por J aime Guzmán, en la elaboración de la Constitución de 1980. Se argumenta que ella, basada en un concepto de "democracia protegida", es apoyada por la derecha pues protege sus intereses de largo plazo y garantiza políticamente su preservación.

Por último, se discuten las similitudes y diferencias entre la derecha pre-1973 y esta "nueva derecha". La autora sostiene que existen importantes continuidades. Primero, por cuanto conserva su carácter pragmático, al mantener su capacidad de negociar para preservar sus intereses de largo plazo. Segundo, pues existen importantes similitudes entre la UDI y el Partido Conservador y entre Renovación Nacional y el Partido Liberal. A ello, agrega que este nuevo bipartidismo no responde a una representación diferenciada de intereses, "pues la élite empresarial sigue estando interrelacionada y tiene sus intereses diversificados en todos los sectores de la economía, al igual que a mediados del siglo XX" (Correa Sutil, 2005: 283). En tercer lugar, se discute el carácter democrático de la derecha, indicándose que éste no es esencial a ella. En concreto, se dice que si antes fue muy respetuosa del orden democrático, fue porque tenía otros instrumentos para defenderse, pero luego, cuando los perdió, buscó otras formas para defender sus intereses. 
Al finalizar, la autora concluye que la nueva derecha ha logrado convocar a amplios sectores tras un proyecto que es funcional a sus intereses y que ha logrado ser hegemónica "respecto a los principios de orden económico, social y político" (Correa Sutil, 2005: 284), habiendo impuesto un modelo que hoy sería compartido por todos.

De esta manera, el libro de Sofía Correa es ciertamente una contribución valiosa. Esto, no sólo por aportar a la literatura sobre nuestra historia política, sino también por enriquecer el debate al exponer nuevas interpretaciones sobre algunos hechos, como fue la creación de la CORFO. Al mismo tiempo, tiene el valor de sugerir interesantes líneas de investigación futura. Una de ellas, por ejemplo, consistiría en estudiar empíricamente cómo se estructura esta nueva derecha y qué elementos la componen, de forma de determinar con precisión los elementos de continuidad y cambio existentes en ella en comparación con la que existió hasta 1973.

Sin perjuicio de lo anterior, el libro presenta algunas debilidades. Por un lado, no analiza con la profundidad necesaria la estrategia y el comportamiento de la derecha desde 1965. Conforme se afirma en el libro, la derecha experimentó en ese tiempo un cambio profundo en relación a su valoración del sistema democrático, pasando de ser su defensora a abogar directamente por una intervención militar. Dada la magnitud de esa transformación, era necesario un estudio más profundo acerca de cómo esta se generó, de la forma en que la derecha fue definiendo su estrategia ante la agudización del conflicto a partir de 1970 y de su rol en la caída de la democracia.

Otro punto débil está en la parte relativa al surgimiento y las características de los partidos de la "nueva derecha", pues si bien se exponen ciertos antecedentes respecto a la formación de la UDI, se extraña un análisis a fondo de la forma en que ambos partidos surgieron y se estructuran, especialmente en el caso de Renovación Nacional, y qué elementos definen las relaciones entre ellos.

Subrayo estos dos temas, pues creo que es útil y necesario estudiarlos con mayor profundidad. Esto con el objeto de aumentar nuestro conocimiento sobre la estructura y características de este importante actor político, especialmente respecto a cómo los cambios que experimentó entre 1964 y 1989 contribuyen a definir sus características y estrategias actuales.

Con todo, estas debilidades no le restan mérito a la obra, por cuanto constituye un excelente aporte a la discusión académica y nos ayuda a aumentar nuestro conocimiento sobre nuestra historia política.

Ricardo Gamboa

Instituto de Estudios Internacionales

Universidad de Chile 